\title{
Polytrauma in geriatric patients: incidence and mortality
}

\author{
F Famà, L M Murabito*, A Beccaria, F Cucinotta, A Caruso, C D Foti, G Versace, N La Torre, C Estollere, P Placanica, \\ M A Gioffrè Florio
}

From XXIII Annual Meeting of the Italian Society of Geriatric Surgery

Lecce, Italy. 2-4 December 2010

\section{Background}

The increase of traumatic events involving geriatric patients is due to longer life expectancy and a progressive improvement of quality of life. More and more elderly subjects carry out various activities, however because of physical frailty, activity exposes them to the risk of injuries and accidents. They are more susceptible to traumatic injuries of road traffic accidents. Our objective was to analyze how increased age and the presence of several related diseases have contributed to an increase in the incidence of multiple trauma in the last 3 years.

\section{Materials and methods}

In the period January 2007 - October 2010, in our UOC MCAU with $\mathrm{OB}$, adequately equipped for major trauma with a Trauma area and RED area with two Shock Rooms, 126304 total referrals were recorded. The percentage of geriatric patients ( $\geq 65$ years) was $25.73 \%$ $(\mathrm{N}=32501)$, amongst these 3067 (2.42\% of total referrals) had medium-severe injuries from domestic or road traffic accidents (Fig.1).

\section{Results}

We observed that the incidence of geriatric trauma has remained constant every year, with a majority of females over males (F/1981-M/1086) (Fig.2) and that the age group most affected is between 75 and 84 years. The 3067 patients we observed: head trauma was present in 1297 patients (42.3\%), head and/or facial trauma 293 (9.6\%), followed by thoracic trauma $242(7.9 \%)$ and/or

\footnotetext{
* Correspondence: letimura@alice.it

Unità Operativa Complessa di Medicina e Chirurgia d'Accettazione e d'Urgenza con Osservazione Breve - Azienda Ospedaliera Universitaria "G.
} Martino" di Messina, Italy

(C) 2011 Famà et al; licensee BioMed Central Ltd. This is an open access article distributed under the terms of the Creative Commons Attribution License (http://creativecommons.org/licenses/by/2.0), which permits unrestricted use, distribution, and reproduction in any medium, provided the original work is properly cited.

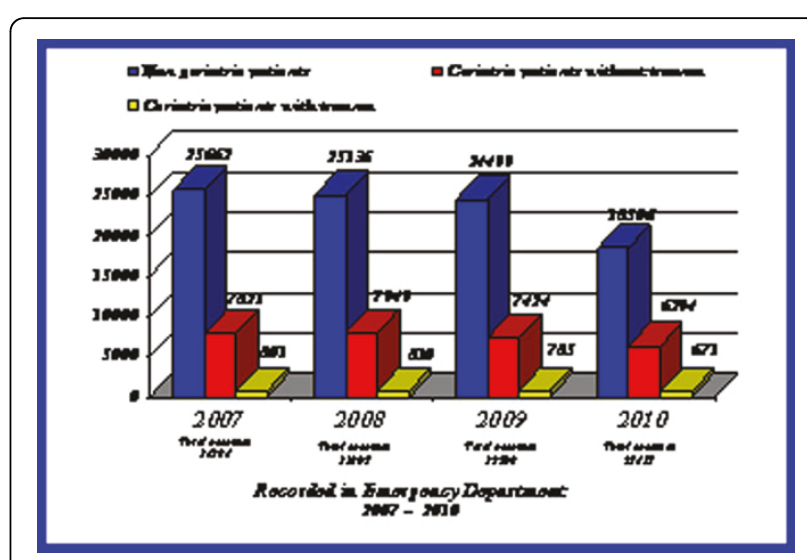

Figure 1 Injuried patients recorded in our Emergency Department from 2007 to 2010

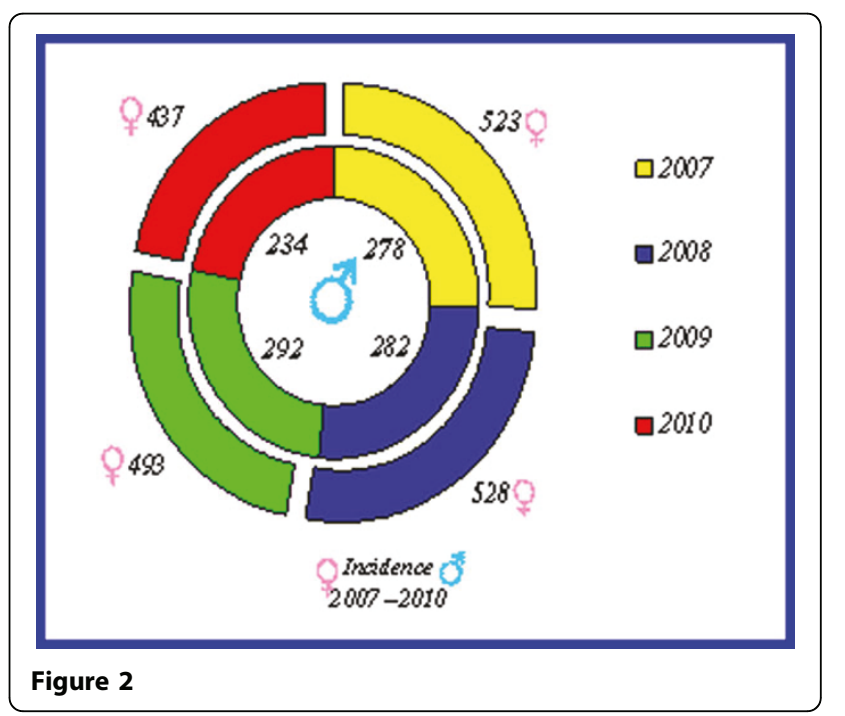




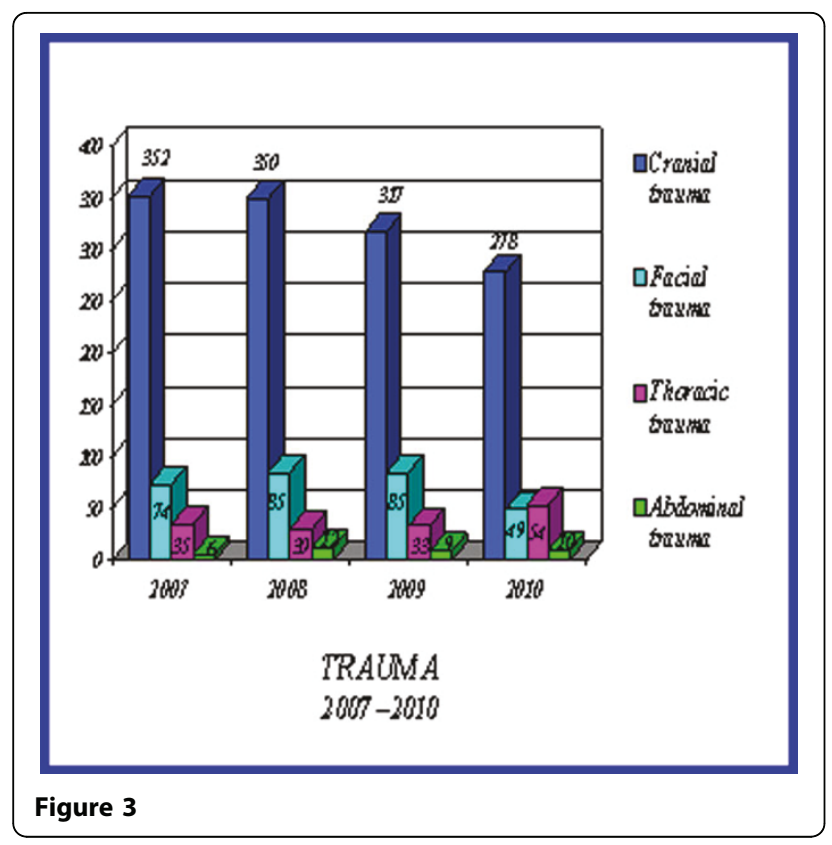

abdominal trauma 37 (1.2\%), often associated with single or multiple fractures (Fig.3).

The most recurrent fracture was the fracture of the femur 513 (16.72\%), especially in women (possibly secondary to osteoporosis).

Also numerous were fractures of the upper limbs $(\mathrm{N}=474)$ and rib fractures $(\mathrm{N}=333)$. In $40 \%$ of cases (1227) the trauma was related to a syncope event. 1981 patients required hospitalization, predominantly in Orthopaedics and Traumatology $(\mathrm{N}=582)$, in neurological wards $(\mathrm{N}=170)$, in Thoracic Surgery $(\mathrm{N}=107)$ and 235 in other departments. In the Emergency Department (UOC MCAU with OB), no death for geriatric trauma was observed.

\section{Conclusions}

The most frequent traumatic event is represented by falls, often associated with syncopal events, very frequent syndrome in geriatrics. In road traffic trauma, the geriatric patient is more often a pedestrian, therefore, the risk of back injuries and fractures is significantly higher, and the risk of permanent disability or death is high.

Published: 24 August 2011

\section{References}

1. Gioffrè Florio M, Fama F, Gullo G, Buccheri G, Beccaria A, Caruso A, Cucinotta F, Estollo C, Malara C, Mamo M, Manti L, P Placanica, Versace G: The management of polytrauma: our experience. Chir Ital 2005 57(4):485-9.

2. Streubel PN, Ricci WM, Wong A, Gardner MJ: Mortality After Distal Femur Fractures in Elderly Patients. Clin Orthop Relat Res 2010, 10.

3. Teixeira A, Trinquart L, Raphael M, Bastianic T, Chatellier G, Holstein J: Outcomes in older patients after surgical treatment for hip fracture: a new approach to characterise the link between readmissions and the surgical stay. Age Ageing 2009, 38(5):584-9.

4. Juliebø V, Bjøro K, Krogseth M, Skovlund E, Ranhoff AH, Wyller TB: Risk factors for preoperative and postoperative delirium in elderly patients with hip fracture. J Am Geriatr Soc 2009, 57(8):1354-61.

doi:10.1186/1471-2318-11-S1-A13

Cite this article as: Famà et al:: Polytrauma in geriatric patients: incidence and mortality. BMC Geriatrics 2011 11(Suppl 1):A13.

\section{Submit your next manuscript to BioMed Central} and take full advantage of:

- Convenient online submission

- Thorough peer review

- No space constraints or color figure charges

- Immediate publication on acceptance

- Inclusion in PubMed, CAS, Scopus and Google Scholar

- Research which is freely available for redistribution 